\title{
BMJ Open Oral antidiabetic medication adherence and glycaemic control among patients with type 2 diabetes mellitus: a cross- sectional retrospective study in a tertiary hospital in Saudi Arabia
}

\author{
Bander Balkhi, ${ }^{1}$ Monira Alwhaibi, ${ }^{1}$ Nasser Alqahtani, ${ }^{2}$ Tariq Alhawassi, ${ }^{1,3}$ \\ Thamir M Alshammari, ${ }^{3,4}$ Mansour Mahmoud, ${ }^{5}$ Mansour Almetwazi, ${ }^{1}$ Sondus Ata, ${ }^{6}$ \\ Khalid M Kamal ${ }^{7}$
}

To cite: Balkhi B, Alwhaibi M, Alqahtani N, et al. Oral antidiabetic medication adherence and glycaemic control among patients with type 2 diabetes mellitus: a cross-sectional retrospective study in a tertiary hospital in Saudi Arabia. BMJ Open 2019;9:e029280. doi:10.1136/ bmjopen-2019-029280

- Prepublication history for this paper is available online To view these files, please visit the journal online (http://dx.doi org/10.1136/bmjopen-2019029280).

Received 25 January 2019 Revised 20 June 2019 Accepted 3 July 2019

Check for updates

(c) Author(s) (or their employer(s)) 2019. Re-use permitted under CC BY-NC. No commercial re-use. See rights and permissions. Published by BMJ.

For numbered affiliations see end of article.

Correspondence to

Dr Bander Balkhi;

bbalkhi@ksu.edu.sa

\section{ABSTRACT}

Objectives The purpose of this study is to measure the adherence rates of oral antidiabetic drugs (OADs) in patients with type 2 diabetes mellitus (T2DM) and assess the relationship of glycaemic control and adherence to OADs after controlling for other associated factors.

Design Cross-sectional retrospective study.

Setting Large tertiary hospital in the central region of Saudi Arabia.

Participants 5457patients aged 18 years and older diagnosed with T2DM during the period from 1 January 2016 to 31 December 2016.

Primary and secondary outcome measures The modified medication possession ratio (mMPR) was calculated as a proxy measure for adherence of OADs. The factors associated with OADs non-adherence and medication oversupply were assessed using multinomial logistic regression models. The secondary outcomes were to measure the association between OADs adherence and glycaemic control.

Results Majority of patients with T2DM were females $(n=3400,62.3 \%)$. The average glycated haemoglobin was $8.2 \pm 1.67$. Among the study population, $48.6 \%$ had good adherence (mMPR $>0.8$ ) and $8.6 \%$ had a medication oversupply (mMPR >1.2). Good adherence was highest among those using repaglinide $(71.0 \%)$ followed by pioglitazone $(65.0 \%)$ and sitagliptin $(59.0 \%)$. In the multivariate analysis, women with T2DM were more likely to have poor adherence $($ adjusted OR $(\mathrm{AOR})=0.76,95 \%$ $\mathrm{Cl}=0.67,0.86$ ) compared with men. Also, medication oversupply was more likely among patients with hyperpolypharmacy $(\mathrm{AOR}=1.88,95 \% \mathrm{Cl}=1.36,2.63)$, comorbid osteoarthritis (AOR=1.72, 95\% $\mathrm{Cl}=1.20,02.45$ ) and non-Saudi patients $(A O R=1.53,95 \% \mathrm{Cl}=1.16,2.01)$. However, no association was found between glycaemic control and adherence to OADs.

Conclusion The study findings support the growing concern of non-adherence to OADs among patients with T2DM in Saudi Arabia. Decision makers have to invest in behavioural interventions that will boost medication adherence rates. This is particularly important in patients
Strengths and limitations of this study

- This study provides a real insight into the current status of medication adherence rates among patient with type 2 diabetes mellitus (T2DM) in Saudi Arabia.

- Using real-world data of more than 5000 patients with T2DM in Saudi Arabia, the study assesses the impact of adherence among different patient subgroups.

- This study did not control the severity of diabetes or diabetes complications, which may affect the rate of adherence to oral antidiabetic drugs (OADs).

- This study indirectly measured adherence to OADs using patient electronic health records, which may not reflect the actual adherence rate.

- Findings from this study cannot be generalised to different populations and settings.

with polypharmacy and high burden of comorbid conditions.

\section{INTRODUCTION}

Type 2 diabetes mellitus (T2DM) is a highly prevalent chronic progressive disorder characterised by high glucose levels in the blood. ${ }^{1}$ The estimated global prevalence in the adult population was $8.8 \%$ in $2015^{2}$ and is projected to increase to $10.4 \%$ by $2040 .^{2}$ In Saudi Arabia, the estimated prevalence of T2DM is approximately $23 \%^{34}$ with another $25.5 \%$ of the population (30 years and older) classified as pre-diabetes. By 2035, the prevalence of T2DM in Saudi Arabia is projected to double and is expected to reach an estimated 7.5 million cases. ${ }^{5}$ While diabetes is projected to be the seventh leading cause of mortality and disability worldwide by $2030,{ }^{6}$ it is already the sixth leading cause of death 
in Saudi Arabia based on the WHO report. ${ }^{7}$ It is well established that uncontrolled T2DM is associated with negative health consequences such as blindness, kidney failure, lower limb amputation and other complications, all of which result in poor quality of life in patients. ${ }^{89}$ Also, T2DM is a well-established risk factor for cardiovascular disease (CVD) and macrovascular complications including costly conditions like coronary heart disease, stroke, nephropathy, retinopathy and others. ${ }^{10}{ }^{11} \mathrm{~A}$ meta-analysis concluded that the risk of CVD in patients with diabetes was three times compared with those without diabetes. ${ }^{11}$

Worldwide, diabetes imposes a large economic burden on the individuals and national healthcare systems. A recent study estimated the global cost of diabetes in adult patients at US $\$ 1.31$ trillion, which represents $1.8 \%$ of the global gross domestic product. ${ }^{12}$ Two-third of this cost was direct medical cost while the remaining one-third was attributable to indirect cost such as loss in productivity. ${ }^{12}$ In the Middle East and North Africa regions, the rising prevalence of diabetes is projected to increase the healthcare cost by $67 \%$ by $2045 .{ }^{3}$ Similar trends are being observed in Saudi Arabia as well and the medical healthcare expenditure for people with diabetes is 10 times higher (US\$3686 vs US\$380) than those without the condition. ${ }^{13}$ Diabetes and its complications also result in high indirect costs such as costs related to absenteeism, loss of productivity, disability and premature mortality. The overall economic burden of diabetes in Saudi Arabia is substantial with an estimated direct cost of 17 billion Saudi Riyals (US $\$ 4.5$ billion) in 2014, which is expected to increase to 43 billion Saudi Riyals (US $\$ 11.4$ billion) in the future. ${ }^{14}$

Patient adherence to recommended treatment regimen is one of the key contributors to quality health outcomes in T2DM. The benefits of drug therapy in terms of improved glycaemic control and subsequent reduction in microvascular, macrovascular complications and morbidity have been fairly demonstrated. Adherence to oral antidiabetic drugs (OADs) is associated with better glycaemic control, ${ }^{15}{ }^{16}$ reduced risk of diabetes complications and reduced economic burden. ${ }^{17} 18$ Investigators in Spain reported that a change in glycated haemoglobin (HbAlc) between the first and last patient visits was largely driven by OADs adherence in $13 \%$ of the cases. ${ }^{19}$ In Saudi Arabia, nearly $56 \%$ of patients have been shown to have low medication adherence. ${ }^{20}$

Although poor adherence (medication underuse) is a well-recognised issue in any healthcare setting, having excess supply of medications than needed (medication oversupply) may also lead to negative health outcomes such as increase in toxicity risks, inefficient use of available healthcare resources and increase in unnecessary healthcare costs. ${ }^{21}$ Prevalence of oversupply has been shown to vary across different institutions, medication classes and countries and ranges from $11 \%$ to $53 \% .{ }^{22}$ Medication oversupply was common, especially among T2DM patients, which may increase the risk of hospitalisation ${ }^{23-26}$ and further influence achieving the recommended level of HbA1c. ${ }^{27}$

With the prevalence of T2DM increasing at an alarming rate in Saudi Arabia, there is an urgent need to address non-adherence to positive interventions, such as OADs, so as to reign in the rapid escalation of healthcare costs and improve patient outcomes. Although several studies have measured the adherence and oversupply rate in patients with diabetes, their prevalence among patients with T2DM in Saudi Arabia along with their impact on glycaemic control is largely unknown. ${ }^{28-31}$ The purpose of this study was to evaluate adherence to OADs and to explore the variables associated with OADs non-adherence in patients with type 2 diabetes. The association between glycaemic control and adherence to OADs will also be examined.

\section{METHODS}

\section{Study design and setting}

A retrospective study was conducted in King Saud University Medical City (KSUMC), the largest tertiary teaching hospital located in the central region of Saudi Arabia. KSUMC is equipped with more than 1200 beds and provides a wide array of medical services. The patient population is composed mainly of Saudi citizens who are predominantly residents of the capital city Riyadh but the hospital also serves as a referral centre for the whole country. The study was approved by the institutional review board (IRB) at KSUMC (IRB number: E-16-2203).

\section{Data sources}

Patients with a recorded diagnosis of T2DM (using International Classifications of Diseases-ninth edition, Clinical Modification codes) and receiving OADs at outpatient clinics of KSUMC were retrospectively identified from the electronic health records (EHRs) for the period 1 January-30 December 2016. The extracted data included demographic information (age, gender, marital status, nationality), laboratory data (HbAlc) and prescription data (name of prescription filled; dispensing date; quantity of drug; number of days supplied and refills). All the data were extracted from the EHRs and there was no direct involvement of any patient in the study. Patient consent was therefore not required and all study variables were collected retrospectively and anonymously (de-identified data) from EHRs.

\section{Study population}

Patients aged 18 years and older with T2DM who had received their treatment at outpatient clinics at KSUMC during the study period had at least two prescription fills for one of the following OADs: sulfonylureas (glibenclamide); biguanides (metformin), thiazolidinediones (pioglitazone), meglitinide analogues (repaglinide), glucosidase inhibitor (acarbose), oral dipeptidyl peptidase-4 inhibitor (sitagliptin) and combination therapy were included in the study. Patients on insulin or incretin 
mimetics (liraglutide injection) and those without at least one $\mathrm{HbAlC}$ value were excluded from this study.

\section{Patient and public involvement}

Patients and public were not involved in the design or conduct of this study.

\section{OUTCOME MEASURES}

\section{Primary outcome: adherence to OADs}

The modified medication possession ratio (mMPR) was used as a proxy to measure the adherence rate in this study. The mMPR was chosen as it is one of the most commonly reported adherence assessment method using EHRs and administrative claims data in the literature. ${ }^{24}{ }^{32-35}$ Also, as one of the aims of this study is to estimate the oversupply rate, mMPR allows for calculation of medication oversupply over $100 \%$ while in other assessment methods such as the proportion of days covered, any medication oversupply (over $100 \%$ ) is truncated. ${ }^{36}$ The mMPR was calculated as the sum of the total days supply for all OADs fills divided by the sum of the number of days covered and the last refill days. ${ }^{18}{ }^{19}$ The date of the first prescription fill was designated as the index date. The total days supplied for each OAD was calculated from the index date until the end of 2016. Patients were considered adherent to their medication regimen if the estimated $\mathrm{mMPR} \geq 0.8$. Otherwise, the patients were deemed as poorly adherent. An mMPR value greater than 1 indicated that the patients filled their medications early before entirely consuming their preceding stock of medications; thus, they had excessive medications than needed. Medication oversupply was defined as $\mathrm{mMPR} \geq 1.2$; the cut-off point of $20 \%$ difference in supply has been reported as an acceptable range in several studies. ${ }^{23}{ }^{25}$ In this study, adherence was categorised into: poor adherence $(\mathrm{mMPR}<0.8)$, good adherence (mMPR $\geq 0.8$ to $<1.2$ ) and oversupply (mMPR $\geq 1.2) .{ }^{37}$ The mMPR was calculated separately for each OAD prescribed during the 12-month study period. Then, an average mMPR was calculated with equal weighting of each drug class.

\section{Secondary outcome: association between OADs adherence and glycaemic control}

The secondary outcome of glycaemic control was based on the patient's last HbA1c reading. The American Diabetes Association Standards of Care has recommended that HbA1c $<7 \%$ should be the glycaemic goal for adults with T2DM. ${ }^{38}$ Using this threshold, the HbA1c was classified into two categories: $<7 \%$ indicating good glycaemic control and $\geq 7 \%$ indicating poor glycaemic control. The last HbA1c reading was used to determine the relationship between adherence and glycaemic control.

\section{Independent variables}

Independent variables included age groups, gender, marital status, nationality and diagnosed comorbid chronic conditions (hypertension, heart failure, ischaemic heart disease, dyslipidaemia, cancer, chronic kidney disease, asthma, osteoarthritis, osteoporosis, depression and anxiety).${ }^{390}$ In addition, polypharmacy was calculated for each patient in this study. Although there is no consensus on the threshold regarding the number of medications used by patients to be considered as polypharmacy, the most accepted definition of polypharmacy is the use of five or more drugs. ${ }^{41}$ Based on this threshold, polypharmacy was categorised as hyperpolypharmacy ( $\geq 10$ medications), major polypharmacy (5-9 medications) and minor polypharmacy (2-4 medications).

\section{Statistical analysis}

Descriptive statistics (frequency and percentages) were used to summarise the categorical variables (sex, marital status, nationality, polypharmacy and co-existing chronic conditions) and means and SD were calculated for continuous variables (age). $\mathrm{X}^{2}$ tests were utilised to determine the factors associated with adherence and only significant factors were used in the regression models. The factors associated with non-adherence and medication oversupply were assessed using multinomial logistic regression models after adjusting for independent variables (age, gender, nationality, marital status and co-existing chronic conditions). The multinomial logistic regression is an extension of binomial logistic regression to allow for a dependent variable with more than two categories of the outcome measure (eg, good adherence, poor adherence and oversupply). All statistical analyses were conducted using the Statistical Analysis Software V.9.2 and an a priori significance level was set at $\mathrm{p}<0.05$.

\section{RESULTS}

A total of 5457 patients with T2DM were identified for year 2016 with a majority of them being women $(n=3400$, $62.3 \%)$ and adults 60 years and older $(\mathrm{n}=2358 ; 43.2 \%)$. More than half of the sample had co-existing chronic conditions, with hypertension $(65.6 \%)$ and dyslipidaemia $(66.0 \%)$ being the most common conditions. Around $59.8 \%$ of patients had major polypharmacy with $18.7 \%$ having hyperpolypharmacy. The average HbAlc was $8.2 \pm 1.67$. Table 1 presents the demographic and clinical characteristics of the study population. Overall, the vast majority (89.2\%) of adults with T2DM were using metformin followed by sitagliptin (23.5\%), glibenclamide $(16.5 \%)$ and pioglitazone (12.1\%) (table 2).

\section{OADs adherence}

Among the study population, $48.6 \%$ had good adherence to $\mathrm{OAD}$ (mMPR $>0.8$ to $<1.2$ ), $42.8 \%$ had poor adherence $(\mathrm{mMPR}<0.8)$ and $8.6 \%$ had medication oversupply $(\mathrm{mMPR}>1.2)$ (table 1). A significantly higher rate of poor adherence was reported among women when compared with men $(45.2 \%$ vs $38.9 \%$, $p$ value $=0.0001)$. OADs oversupply was significantly higher among patients with heart failure $(24.2 \%)$, ischaemic heart disease (16.8\%), chronic kidney disease $(21.6 \%)$, osteoarthritis $(12.3 \%)$, anxiety 
Table 1 Characteristics of the study population and number and row percentage of characteristics by adherence level among adults with diabetes

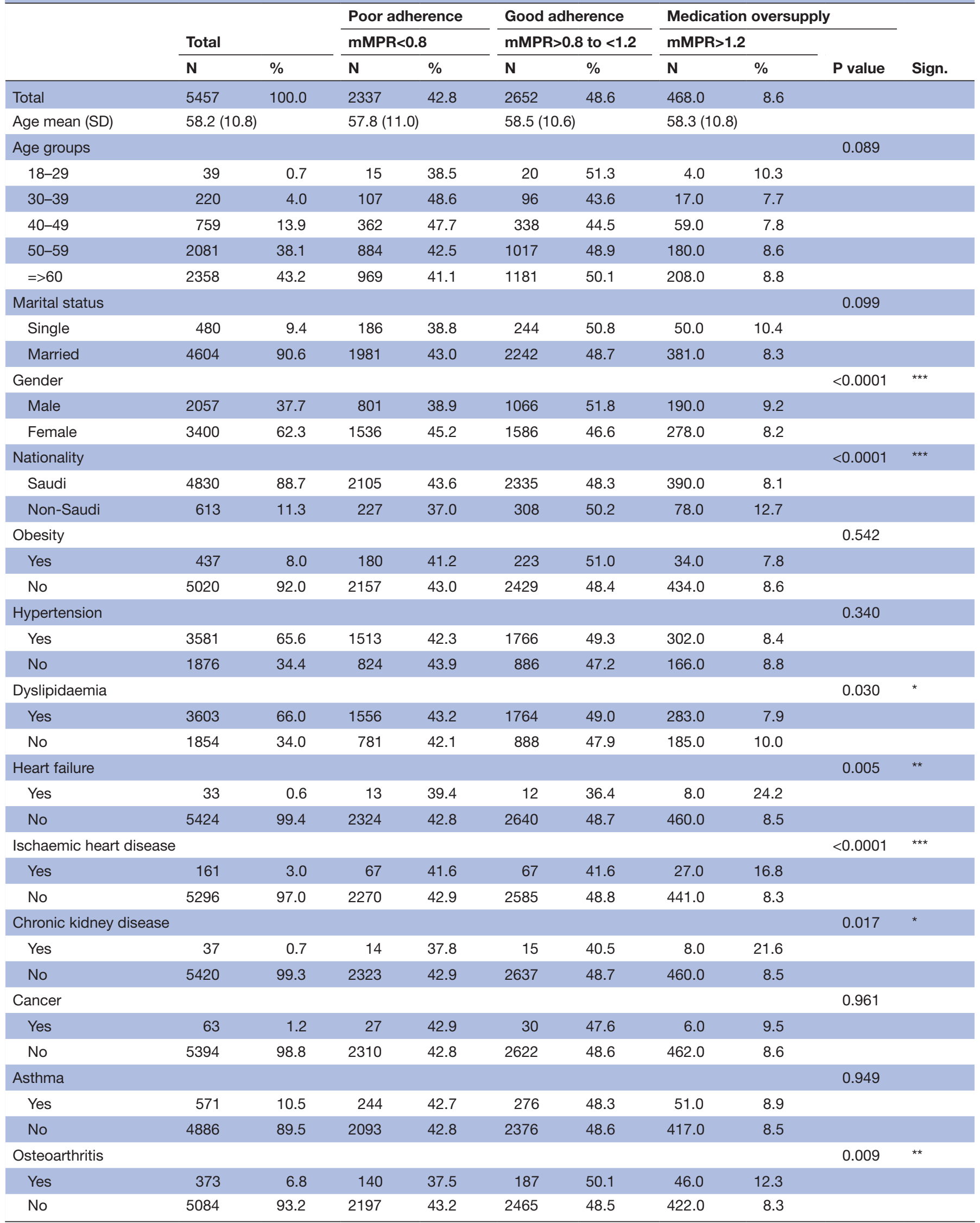

Continued 
Table 1 Continued

\begin{tabular}{|c|c|c|c|c|c|c|c|c|c|c|}
\hline & & & \multirow{2}{*}{\multicolumn{2}{|c|}{$\begin{array}{l}\text { Poor adherence } \\
\text { mMPR }<0.8\end{array}$}} & \multirow{2}{*}{\multicolumn{2}{|c|}{$\begin{array}{l}\text { Good adherence } \\
\text { mMPR }>0.8 \text { to }<1.2\end{array}$}} & \multirow{2}{*}{\multicolumn{2}{|c|}{$\begin{array}{l}\text { Medication oversupply } \\
\text { mMPR }>1.2\end{array}$}} & \multirow{3}{*}{ P value } & \multirow[b]{3}{*}{ Sign. } \\
\hline & \multicolumn{2}{|l|}{ Total } & & & & & & & & \\
\hline & $\mathbf{N}$ & $\%$ & $\mathbf{N}$ & $\%$ & $\mathbf{N}$ & $\%$ & $\mathbf{N}$ & $\%$ & & \\
\hline Yes & 199 & 3.6 & 97 & 48.7 & 89 & 44.7 & 13.0 & 6.5 & & \\
\hline No & 5258 & 96.4 & 2240 & 42.6 & 2563 & 48.7 & 455.0 & 8.7 & & \\
\hline No & 5173 & 94.8 & 2223 & 43.0 & 2523 & 48.8 & 427.0 & 8.3 & & \\
\hline Depression & & & & & & & & & 0.640 & \\
\hline Yes & 100 & 1.8 & 40 & 40.0 & 49 & 49.0 & 11.0 & 11.0 & & \\
\hline No & 5357 & 98.2 & 2297 & 42.9 & 2603 & 48.6 & 457.0 & 8.5 & & \\
\hline Minor polypharmacy & 1172 & 21.5 & 506 & 43.2 & 574 & 49.0 & 92.0 & 7.8 & & \\
\hline $\begin{array}{l}\text { Average } \mathrm{HbA} 1 \mathrm{C} \text { mean } \\
\text { (SD) }\end{array}$ & $8.2(1.67)$ & & $8.1(1.67)$ & & $8.2(1.66)$ & & $8.3(1.66)$ & & & \\
\hline Glycaemic control & & & & & & & & & 0.005 & ** \\
\hline $\begin{array}{l}\text { Good glycaemic } \\
\text { control }\end{array}$ & 1231 & 698 & 698 & 46.9 & 671 & 45.1 & 119 & 8.0 & & \\
\hline $\begin{array}{l}\text { Poor glycaemic } \\
\text { control }\end{array}$ & 4224 & 1076 & 1076 & 41.9 & 1290 & 50.2 & 204 & 7.9 & & \\
\hline
\end{tabular}

Study population comprised of 5457 adults with type 2 diabetes mellitus. mMPR, modified medication possession ratio; N, number; Sign., significance. Asterisks $\left(^{*}\right)$ represent significant differences based on mMPR from $\mathrm{X}^{2}$ tests.

${ }^{* * *} \mathrm{p}<0.001 ;{ }^{* *} 0.001 \leq \mathrm{p}<0.01 ;{ }^{*} 0.01 \leq \mathrm{p}<0.05$.

(14.4\%) and depression (11.0\%) when compared with those without these comorbid conditions. Medication oversupply was also significantly higher among patients with hyperpolypharmacy when compared with those without polypharmacy $(13.5 \%$ vs $7.8 \%$, p value $=0.0001)$. The medication oversupply rate was highest for acarbose $(17.1 \%)$ followed by pioglitazone $(15.4 \%)$ and glibenclamide $(13.9 \%)$ (table 2$)$.
OADs adherence and glycaemic control

Results show that good adherence was highest among those who used repaglinide $(71.0 \%)$ followed by pioglitazone $(65.0 \%)$ and sitagliptin (59.0\%) (table 2). Also, this study found no significant association between medication adherence with any OADs and glycaemic control (table 3). However, a higher rate of good glycaemic

Table 2 Frequency and percentage of OADs and comparison between medication possession ratio, modified (mMPR)

\begin{tabular}{lrrllllr}
\hline & N & $\%$ & $\begin{array}{l}\text { Mean } \\
\text { adherence }\end{array}$ & SD & $\begin{array}{l}\text { Poor } \\
\text { adherence }\end{array}$ & $\begin{array}{l}\text { Good } \\
\text { adherence }\end{array}$ & $\begin{array}{l}\text { Oversupply } \\
\text { rate }\end{array}$ \\
\hline Acarbose & 205 & 3.8 & 0.97 & 0.31 & $24.9 \%$ & $58.1 \%$ & $17.1 \%$ \\
Metformin & 4869 & 89.2 & 0.79 & 0.31 & $48.1 \%$ & $43.3 \%$ & $8.6 \%$ \\
Glibenclamide & 901 & 16.5 & 0.93 & 0.29 & $29.5 \%$ & $56.6 \%$ & $13.9 \%$ \\
Sitagliptin & 1285 & 23.5 & 0.92 & 0.27 & $28.9 \%$ & $59.9 \%$ & $11.2 \%$ \\
Repaglinide & 46 & 0.8 & 0.97 & 0.21 & $17.5 \%$ & $71.7 \%$ & $10.8 \%$ \\
Pioglitazone & 662 & 12.1 & 0.97 & 0.27 & $19.6 \%$ & $65.0 \%$ & $15.4 \%$ \\
Combination & 410 & 7.5 & 0.84 & 0.32 & $46.6 \%$ & $43.9 \%$ & $9.5 \%$ \\
\hline
\end{tabular}

Study population comprised of 5457 adults with type 2 diabetes mellitus.

mMPR, modified medication possession ratio; N, number; OADs, oral antidiabetic drugs. 
Table 3 Association between adherence to OADs and glycaemic control

\section{Good glycaemic control Poor glycaemic control}

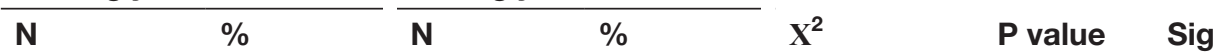

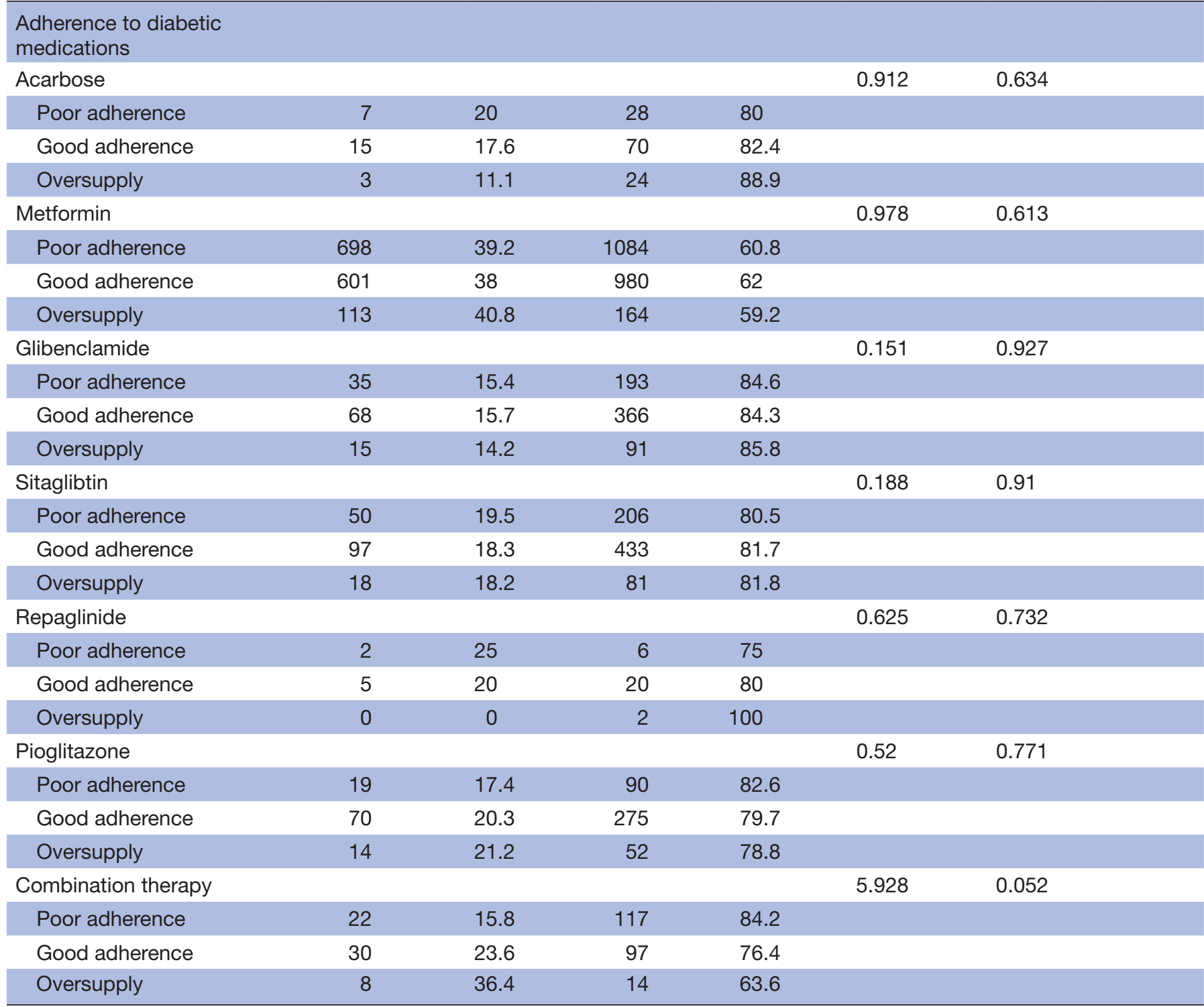

Study population comprised of 5457 Adults with type 2 diabetes mellitus.

OADs: oral antidiabetic drugs; Sig., significance.

control $(\mathrm{HbA} 1 \mathrm{C}<7 \%)$ was observed among patients on metformin $(24.1 \%)$ followed by combination therapy $(12.0 \%)$ and pioglitazone $(11.5 \%)$.

\section{Factors associated with OADs adherence}

The adjusted OR (AOR) and 95\% CI from multinomial logistic regressions on adherence to OADs are presented in table 4. Several factors associated with OADs adherence were identified: gender, nationality, co-existing chronic conditions and polypharmacy. Women with T2DM were less likely to have good adherence (AOR $=0.76,95 \%$ $\mathrm{CI}=0.67,0.86)$ compared with men. Medication oversupply was more likely among T2DM patients with hyperpolypharmacy $(\mathrm{AOR}=1.88,95 \% \mathrm{CI}=1.36,2.63)$, comorbid osteoarthritis $\quad(\mathrm{AOR}=1.72,95 \% \mathrm{CI}=1.20,02.45)$ and non-Saudi patients $(\mathrm{AOR}=1.53,95 \% \mathrm{CI}=1.16,2.01)$.

\section{DISCUSSION}

\section{Medication adherence}

Medication adherence is critical in the treatment of patients with diabetes. Failure to adhere to prescribed medication regimen is recognised as a serious issue resulting in negative consequences to the patient and the healthcare system as well. Thus, there is a need to identify specific barriers that will help in adapting appropriate tools to overcome and improve medication adherence. ${ }^{3542}$ 
Table 4 OR and 95\% Cls from multinomial logistic regression on adherence among adults with type 2 diabetes mellitus

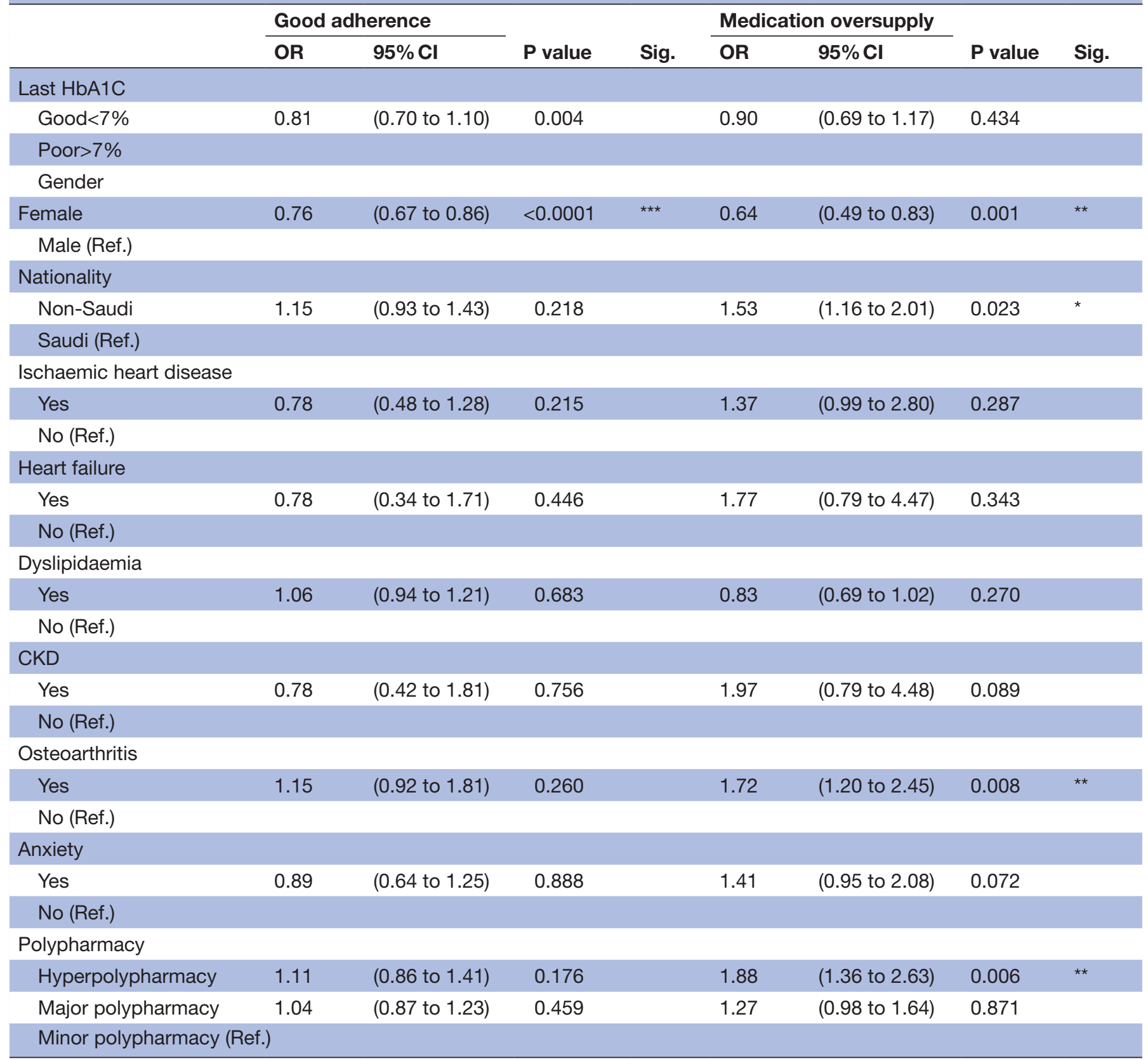

Asterisks $\left(^{*}\right)$ represent significant differences based on adherence from multinomial logistic regressions with poor adherence as the reference group.

${ }^{* \star *} \mathrm{p}<.001 ;{ }^{* \star} .001 \leq \mathrm{p}<.01 ;{ }^{*} .01 \leq \mathrm{p}<.05$

Study population comprised of 5457 adults with type 2 diabetes mellitus.

CKD, chronic kidney disease; HbA1C, glycated haemoglobin; Ref., reference group; Sig., significance.

The heterogeneity, complexity and importance of this issue have been extensively studied and well recognised in the literature. ${ }^{35} 4344$ Several barriers and facilitators of adherence have been identified including patient-related factors (belief and knowledge, cognitive function, health literacy), physician-related factors (communication with patient), medication-related factors (adverse drug reaction, drug regimen complexity, cost) and system-based factors (lack of medication review, lack of patient follow-up). ${ }^{43}$ However, factors associated with non-adherence were not comprehensive and are reported to vary depending on the nature of the disease (eg, severity), patients' characteristics (eg, demographic and socioeconomic status). ${ }^{46}$ To explore the issue of medication non-adherence in patients with T2DM in Saudi Arabia, this study utilised patients' refill data from EHRs of a tertiary hospital and estimated patients' overall adherence to OADs using mMPR values. The study found that almost half of the study population with T2DM had good adherence $(\mathrm{mMPR}>0.8)$. In the published 
literature, good adherence has been shown to vary widely and results from a systematic review of 20 retrospective studies demonstrated that adherence to OADs therapy ranged from $36 \%$ to $93 \%$ in patients with diabetes. ${ }^{47}$ These variations in adherence were affected by several factors including the adherence measurement tools, population or institution where the studies were conducted, and the medications included in the studies. ${ }^{44}$

The study findings also revealed that adherence varied widely across different medications with the highest adherence rates observed in patients on repaglinide followed by pioglitazone users and was lowest among metformin users. Several studies have demonstrated that patients on pioglitazone and sulfonylureas have a greater adherence rate than those on metformin. ${ }^{48}$ The side effects of metformin such as flatulence and diarrhoea can possibly be the cause of poor adherence rates among patients. ${ }^{49}$ In this study, women were less likely to be adherent as compared with men, which was not consistent with previous studies that showed women having significantly higher adherence rates than men. ${ }^{50-52}$ However, few studies have demonstrated similar surprising findings in which women have low level of adherence.$^{53-55}$ Some reason reported in the literature indicated that women often prescribed more medication, have a complex medications regimen and experience more side effects which could contribute to lower rates of adherence ${ }^{56}$ Although the actual reason behind these differences in adherence level between men and women warrants further investigation, these differences should be considered in personalised treatment plan in order to improve adherence rate and clinical outcomes. ${ }^{56}$

\section{Medication oversupply}

Another interesting study finding was related to medication oversupply; around $8.6 \%$ of the patients had medication oversupply, in particular, among those with chronic kidney disease and patients with hyperpolypharmacy. In addition to the significant economic burden associated with excessive supply of medications, oversupply of diabetes medications may result in accidental medication errors, which can possibly lead to negative outcomes. ${ }^{57}$ The current study results are consistent with the published studies that reported medication oversupply range from $6.7 \%$ to $13.4 \% .^{23}{ }^{58}$ Medication oversupply could be a result of a number of factors such as sicker patients, medication management system issues, poor medication reconciliation, patients visiting multiple clinicians and miscommunication between the patients and their clinicians. ${ }^{25}{ }^{58}$ It should be noted that KSUMC utilises a 90-day supply for chronic disease, which has been previously reported as being more convenient to the patient and can improve patient adherence. However, it can also increase the chance of the patient having an excess amount of medication, which can lead to oversupply and wastage. This is especially the case when the treatment regimen of a patient has been switched or changed. ${ }^{5859}$
Relationship between adherence to OADs and glycaemic control

There is compelling data to show that glycaemic control is essential in the management of T2DM and it dramatically reduces diabetes-related complications. In the UK Prospective Diabetes Study (UKPDS) trial, the microvascular complication rate was reduced by $25 \%$ and myocardial infarction (MI) by $16 \%$ in the intensive treatment arm. ${ }^{60} \mathrm{~A}$ meta-analysis of the four diabetes trials, Action to Control Cardiovascular Risk in Diabetes, Action in Diabetes and Vascular Disease: Preterax and Diamicron Modified Release Controlled Evaluation, UKPDS and Veterans Affairs Diabetes Trial, showed a $15 \%$ reduction of relative risk in non-fatal MI with every $1 \%$ decrease in HbA1c. ${ }^{61}$ A retrospective cohort study reported that medication adherence was associated with better glycaemic control by one and a half folds when compared with non-adherent patients. ${ }^{62}$ Not surprisingly, poor adherence to OADs was associated with poor glycaemic control as documented by many published studies. ${ }^{6364}$ This study reported that around two-thirds of patients with T2DM failed to achieve adequate glycaemic control, which is consistent with another published study in Saudi Arabia, ${ }^{65}$ but had higher than the average global HbAlc levels reported in the literature $(45 \%) .{ }^{66}$ However, no significant association between achieving glycaemic control and adherence level was seen in this study.

Poor glycaemic control due to non-adherence to OADs can lead to higher microvascular complications (ie, nephropathy, retinopathy, and neuropathy), ${ }^{67}$ higher macrovascular complications (ie, MI and ischaemic stroke $)^{68}$ and high risk of mortality, ${ }^{68}$ hospitalisation and emergency department visits. ${ }^{16}$ Besides, poor glycaemic control due to non-adherence to OADs can lead to an increased diabetes care cost. In the USA, non-adherence to diabetes medications cost $\$ 337$ billion in $2013 .{ }^{17}{ }^{18} \mathrm{In}$ Saudi Arabia, the economic burden of T2DM compliance and persistence for patients who struggle to achieve optimal therapy is estimated around 3.9 billion Saudi Riyals (US\$1.04 billion) and the cost is expected to significantly increase in the future. ${ }^{69}$ The value of adherence to pharmacologic treatments in achieving and controlling diabetes has clearly been established. Good adherence can mitigate the risk of hospitalisation, emergency room visits, ${ }^{70}$ all-cause mortality ${ }^{71}$ and could improve the overall glycaemic control. ${ }^{151672}$

\section{Strengths and limitations}

Adherence can be measured by different methodological approaches. In this study, adherence was assessed using the MMPR method, which is a reliable method and depends on real-world data obtained from patient's medication refill history. This method can be used for a large population at a relatively low cost and also prevents recall bias, which is associated with patient interview-based adherence methods. This study sheds some light into concomitant diseases that were associated with OADs non-adherence. Although the current study provides 
real-world information from more than 5400 patients about adherence rate to different OADs and the relationship of OADs and glycaemic control, few limitations were observed. The study population was mostly patients who attended the KSUMC in central Saudi Arabia; therefore, it is difficult to extrapolate the study findings to the whole Saudi population residing in the other geographical areas of the country. Nevertheless, patients included in this study represent almost all Saudi citizens and expatriate groups living in Saudi Arabia. In addition, important information, such as health literacy, educational level, economic status, marital status, knowledge about disease and medications thatmight be contributing factors to medication non-adherence, was not available from EHRs. It should be noted that the adherence in this study was based on pharmacy refills data, which only indicates the possession of the medication, but does not capture the actual consumption of the medication by the patient. This is one of the limitations in calculating adherence using pharmacy refills data as it assumes that the medication was actually taken by the patient, which may not necessarily be the case. The main advantage of using the EHRs is the availability of large sample size that can provide precise estimates and availability of dispensing date and quantity dispensed, which is hard to collect from the patients using the patient-reported measures. Other tools that potentially provide more accurate estimation about the actual consumption and adherence include direct measures such as measurement of drug of metabolite in body fluids or testing for biomarkers. However, these are expensive and intrusive to patients and therefore difficult to implement.

\section{Future implications}

Healthcare professionals have to pay special attention to patients with diabetes, especially those with polypharmacy and concomitant diseases, as this will increase the risk for non-adherence to OADs medication. Although we have few patients with medication oversupply in our study, it is worthwhile for healthcare providers and policymakers to be aware of this important issue and to plan for a strategy to prevent both under/over-supply of medications. Further investigations are needed to explore the oversupply across different populations and chronic diseases as the rate could vary significantly. This will allow the estimation of financial loss due to medication oversupply (eg, wastage) and can help implement effective strategies to prevent medication oversupply. In addition, our findings indicated a surprising result regarding the adherence in female with OADs in patient with T2DM, thereby identifying a need to investigate the factors affecting adherence to OADs among females.

\section{Clinical practice implications}

Healthcare providers must remain vigilant when evaluating adherence to OADs medications, by counselling patients at each visit and properly assessing medication adherence as a behaviour. Improving patient-clinician relationships, providing information to guide self-management to support patients with diabetes can provide a clinically significant improvement in glycaemic control for some patients and improve other health outcomes. As medication oversupply was an issue in our study especially among those with comorbid chronic conditions and those with multiple medications, pharmacy services such as reconciliation and medication therapy management are needed to optimise medication use.

\section{CONCLUSIONS}

The study findings support the growing concern of non-adherence to OADs among patients with T2DM in Saudi Arabia. Both providers and pharmacists, in their interaction with the patients, should stress on the importance of adherence and its impact on clinical, economic and humanistic outcomes and also focus on preventive measures such as lifestyle modifications. Decision makers have to invest in behavioural interventions such as motivational interviewing, planned behaviour education and problem-solving training which can boost the adherence rates to medications and reduce medication oversupply. ${ }^{73}$ This is particularly important in patients with polypharmacy or hyperpolypharmacy and high burden of comorbid conditions.

\section{Author affiliations}

${ }^{1}$ Department of Clinical Pharmacy, College of Pharmacy, King Saud University, Riyadh, Saudi Arabia

${ }^{2}$ Drug Sector, Saudi Food and Drug Authority, Riyadh, Riyadh, Saudi Arabia ${ }^{3}$ Medication Safety Research Chair, College of Pharmacy, King Saud University, Riyadh, Saudi Arabia

${ }^{4}$ Department of Clinical Pharmacy, College of Pharmacy, University of Hail, Hail, Saudi Arabia

${ }^{5}$ Department of Clinical and Hospital Pharmacy, College of Pharmacy, Taibah University, Madinah, Saudi Arabia

${ }^{6}$ Investigational Drugs and Research Unit, King Khalid University Hospital, Riyadh, Saudi Arabia

${ }^{7}$ Division of Pharmaceutical, Administrative and Social Sciences, Duquesne University School of Pharmacy, Pittsburgh, USA

Acknowledgements The project was fully supported financially by the Vice Deanship of Research Chairs, King Saud University, Riyadh, Saudi Arabia.

Contributors BB, MA, NA and TMA participated in designing the study. SA and MM reviewed the proposal and obtained ethical approval. BB and MA did the statistical analysis. BB, MA, TA, TMA and KMK contributed to the interpretation of the results. All authors drafted, revised and approved the final version of this manuscript.

Funding The authors have not declared a specific grant for this research from any funding agency in the public, commercial or not-for-profit sectors.

Competing interests None declared.

Patient consent for publication Not required.

Ethics approval The study was approved by the institutional review board under protocol number (E-16-2203).

Provenance and peer review Not commissioned; externally peer reviewed. Data sharing statement No data are available.

Open access This is an open access article distributed in accordance with the Creative Commons Attribution Non Commercial (CC BY-NC 4.0) license, which permits others to distribute, remix, adapt, build upon this work non-commercially, and license their derivative works on different terms, provided the original work is 
properly cited, appropriate credit is given, any changes made indicated, and the use is non-commercial. See: http://creativecommons.org/licenses/by-nc/4.0/.

\section{REFERENCES}

1. American Diabetes Association. Diagnosis and classification of diabetes mellitus. Diabetes Care 2014;37(Supplement 1):S81-S90.

2. Ogurtsova K, da Rocha Fernandes JD, Huang Y, et al. IDF Diabetes atlas: global estimates for the prevalence of diabetes for 2015 and 2040. Diabetes Res Clin Pract 2017;128:40-50.

3. Federation ID. IDF Diabetes atlas. 8th edn. Middle East and North Africa, 2017.

4. Al-Daghri NM, Al-Attas OS, Alokail MS, et al. Diabetes mellitus type 2 and other chronic non-communicable diseases in the central region, Saudi Arabia (Riyadh cohort 2): a decade of an epidemic. BMC Med 2011;9:76.

5. Guariguata L, Whiting DR, Hambleton I, et al. Global estimates of diabetes prevalence for 2013 and projections for 2035. Diabetes Res Clin Pract 2014;103:137-49.

6. Mathers CD, Loncar D. Projections of global mortality and burden of disease from 2002 to 2030. PLoS Med 2006;3:e442.

7. Organization WH. Diabetes country profiles 2016. 2016 http://www. who.int/diabetes/country-profiles/sau_en.pdf?ua=1.

8. Collins AJ, Foley RN, Gilbertson DT, et al. United States renal data system public health surveillance of chronic kidney disease and endstage renal disease. Kidney Int Supp/ 2015;5:2-7.

9. Moxey PW, Gogalniceanu P, Hinchliffe RJ, et al. Lower extremity amputations--a review of global variability in incidence. Diabet Med 2011;28:1144-53.

10. Yau JW, Rogers SL, Kawasaki R, et al. Global prevalence and major risk factors of diabetic retinopathy. Diabetes Care 2012;35:556-64.

11. Sarwar N, Gao P, Seshasai SR, et al. Diabetes mellitus, fasting blood glucose concentration, and risk of vascular disease: a collaborative meta-analysis of 102 prospective studies. Lancet 2010;375:2215-22.

12. Bommer $C$, Heesemann E, Sagalova V, et al. The global economic burden of diabetes in adults aged 20-79 years: a cost-of-illness study. Lancet Diabetes Endocrinol 2017;5:423-30.

13. Alhowaish AK. Economic costs of diabetes in Saudi Arabia. J Family Community Med 2013;20:1.

14. Mokdad AH, Tuffaha M, Hanlon M, et al. Cost of diabetes in the Kingdom of Saudi Arabia, 2014. J Diabetes Metab 2015;6:2.

15. Ho PM, Rumsfeld JS, Masoudi FA, et al. Effect of medication nonadherence on hospitalization and mortality among patients with diabetes mellitus. Arch Intern Med 2006;166:1836-41.

16. Lin LK, Sun Y, Heng BH, et al. Medication adherence and glycemic control among newly diagnosed diabetes patients. BMJ Open Diabetes Res Care 2017;5:e000429.

17. Egede LE, Gebregziabher M, Dismuke CE, et al. Medication nonadherence in diabetes: longitudinal effects on costs and potential cost savings from improvement. Diabetes Care 2012;35:2533-9.

18. Kennedy-Martin T, Boye KS, Peng X. Cost of medication adherence and persistence in type 2 diabetes mellitus: a literature review. Patient Prefer Adherence 2017;11:1103-17.

19. García Díaz E, Ramírez Medina D, García López A, et al. Determinants of adherence to hypoglycemic agents and medical visits in patients with type 2 diabetes mellitus. Endocrinol Diabetes Nutr 2017;64:531-8.

20. Khan AR, Al-Abdul Lateef ZN, Al Aithan MA, et al. Factors contributing to non-compliance among diabetics attending primary health centers in the Al Hasa district of Saudi Arabia. J Family Community Med 2012;19:26.

21. Chaiyakunapruk $N$, Thanarungroj $A$, Cheewasithirungrueng $N$, et al. Estimation of financial burden due to oversupply of medications for chronic diseases. Asia Pac J Public Health 2012;24:487-94.

22. Evans JM, Donnan PT, Morris AD. Adherence to oral hypoglycaemic agents prior to insulin therapy in Type 2 diabetes. Diabet Med 2002;19:685-8

23. Dilokthornsakul P, Chaiyakunapruk N, Nimpitakpong P, et al. Understanding medication oversupply and its predictors in the outpatient departments in Thailand. BMC Health Serv Res 2014; $14: 408$

24. Lau DT, Nau DP. Oral antihyperglycemic medication nonadherence and subsequent hospitalization among individuals with type 2 diabetes. Diabetes Care 2004;27:2149-53.

25. Stroupe KT, Murray MD, Stump TE, et al. Association between medication supplies and healthcare costs in older adults from an urban healthcare system. J Am Geriatr Soc 2000;48:760-8.

26. Stroupe KT, Teal EY, Weiner M, et al. Health care and medication costs and use among older adults with heart failure. Am J Med 2004;116:443-50.
27. Kim N, Agostini JV, Justice AC. Refill adherence to oral hypoglycemic agents and glycemic control in veterans. Ann Pharmacother 2010;44:800-8.

28. Osterberg L, Blaschke T. Adherence to medication. N Engl J Med 2005;353:487-97.

29. Farmer KC. Methods for measuring and monitoring medication regimen adherence in clinical trials and clinical practice. Clin Ther 1999;21:1074-90. Discussion 3.

30. Ho PM, Bryson CL, Rumsfeld JS. Medication adherence: its importance in cardiovascular outcomes. Circulation 2009;119:3028-35.

31. Jimmy B, Jose J. Patient medication adherence: measures in daily practice. Oman Med J 2011;26:155-9.

32. Gordon J, McEwan P, Idris I, et al. Treatment choice, medication adherence and glycemic efficacy in people with type 2 diabetes: a UK clinical practice database study. BMJ Open Diabetes Res Care 2018;6:e000512.

33. Lawrence DB, Ragucci KR, Long LB, et al. Relationship of oral antihyperglycemic (sulfonylurea or metformin) medication adherence and hemoglobin A1c goal attainment for $\mathrm{HMO}$ patients enrolled in a diabetes disease management program. J Manag Care Pharm 2006;12:466-71.

34. Rozenfeld Y, Hunt JS, Plauschinat C, et al. Oral antidiabetic medication adherence and glycemic control in managed care. Am J Manag Care 2008;14:71-5.

35. Capoccia K, Odegard PS, Letassy N. Medication adherence with diabetes medication: a systematic review of the literature. Diabetes Educ 2016;42:34-71.

36. Raebel MA, Schmittdiel J, Karter AJ, et al. Standardizing terminology and definitions of medication adherence and persistence in research employing electronic databases. Med Care 2013;51(8):S11-21.

37. Hess LM, Raebel MA, Conner DA, et al. Measurement of adherence in pharmacy administrative databases: a proposal for standard definitions and preferred measures. Ann Pharmacother 2006;40(78):1280-8.

38. American Diabetes Association. Standards of medical care in diabetes--2014. Diabetes Care 2014;37(Supplement 1):S14-80.

39. Teljeur C, Smith SM, Paul G, et al. Multimorbidity in a cohort of patients with type 2 diabetes. Eur J Gen Pract 2013;19:17-22.

40. Iglay K, Hannachi H, Joseph Howie P, et al. Prevalence and coprevalence of comorbidities among patients with type 2 diabetes mellitus. Curr Med Res Opin 2016;32:1243-52.

41. Monégat M, Sermet C, Perronnin M, et al. Polypharmacy: definitions, measurement and stakes involved: review of the literature and measurement tests. Quest d'économie la santé 2014;204:1-8.

42. Gellad WF, Grenard JL, Marcum ZA. A systematic review of barriers to medication adherence in the elderly: looking beyond cost and regimen complexity. Am J Geriatr Pharmacother 2011;9:11-23.

43. Yap AF, Thirumoorthy T, Kwan YH. Systematic review of the barriers affecting medication adherence in older adults. Geriatr Gerontol Int 2016;16:1093-101.

44. Krass I, Schieback P, Dhippayom T. Adherence to diabetes medication: a systematic review. Diabet Med 2015;32:725-37.

45. Mathes T, Jaschinski T, Pieper D. Adherence influencing factors - a systematic review of systematic reviews. Arch Public Health 2014;72:37

46. Jaam M, Ibrahim MIM, Kheir N, et al. Factors associated with medication adherence among patients with diabetes in the Middle East and North Africa region: a systematic mixed studies review. Diabetes Res Clin Pract 2017;129:1-15.

47. Cramer JA. A systematic review of adherence with medications for diabetes. Diabetes Care 2004;27:1218-24.

48. Hansen RA, Farley JF, Droege M, et al. A retrospective cohort study of economic outcomes and adherence to monotherapy with metformin, pioglitazone, or a sulfonylurea among patients with type 2 diabetes mellitus in the United States from 2003 to 2005. Clin Ther 2010;32:1308-19.

49. McGovern A, Hinton W, Calderara S, et al. A class comparison of medication persistence in people with Type 2 diabetes: a retrospective observational study. Diabetes Ther 2018;9:229-42.

50. Parada H, Horton LA, Cherrington A, et al. Correlates of medication nonadherence among Latinos with type 2 diabetes. Diabetes Educ 2012;38:552-61.

51. Cohen HW, Shmukler C, Ullman R, et al. Measurements of medication adherence in diabetic patients with poorly controlled $\mathrm{HbA}(1 \mathrm{c})$. Diabet Med 2010;27:210-6.

52. Wong MC, Kong AP, So WY, et al. Adherence to oral hypoglycemic agents in 26,782 Chinese patients: a cohort study. J Clin Pharmacol 2011;51:1474-82. 
53. Mahmoud MIH. Compliance with treatment of patients with hypertension in Almadinah Almunawwarah: a community-based study. Journal of Taibah University Medical Sciences 2012;7:92-8.

54. Khayyat SM, Khayyat SM, Hyat Alhazmi RS, et al. Predictors of medication adherence and blood pressure control among Saudi Hypertensive patients attending primary care clinics: a crosssectional study. PLoS One 2017;12:e0171255.

55. Khalil SA, Elzubier AG. Drug compliance among hypertensive patients in Tabuk, Saudi Arabia. J Hypertens 1997;15:561-5.

56. Manteuffel M, Williams S, Chen W, et al. Influence of patient sex and gender on medication use, adherence, and prescribing alignment with guidelines. J Womens Health 2014;23:112-9.

57. Chen $\mathrm{CC}$, Blank RH, Cheng SH. Medication supply, healthcare outcomes and healthcare expenses: longitudinal analyses of patients with type 2 diabetes and hypertension. Health Policy 2014;117:374-81.

58. Thorpe CT, Johnson H, Dopp AL, et al. Medication oversupply in patients with diabetes. Res Social Adm Pharm 2015;11:382-400.

59. Domino ME, Martin BC, Wiley-Exley E, et al. Increasing time costs and copayments for prescription drugs: an analysis of policy changes in a complex environment. Health Serv Res 2011;46:900-19.

60. Genuth S, Eastman R, Kahn R, et al. Implications of the United kingdom prospective diabetes study. Diabetes Care 2003;26:S28-32.

61. Turnbull F, Abraira C, Anderson R, et al. Intensive glucose control and macrovascular outcomes in type 2 diabetes. Springer 2009.

62. McAdam-Marx C, Bellows BK, Unni S, et al. Impact of adherence and weight loss on glycemic control in patients with type 2 diabetes: cohort analyses of integrated medical record, pharmacy claims, and patient-reported data. J Manag Care Spec Pharm 2014;20:691-700.

63. Vichayanrat A, Matawaran BJ, Wibudi A, et al. Assessment of baseline characteristics, glycemic control and oral antidiabetic treatment in Asian patients with diabetes: the registry for assessing OAD usage in diabetes management (REASON) Asia study. $J$ Diabetes 2013;5:309-18.

64. Feldman BS, Cohen-Stavi CJ, Leibowitz M, et al. Defining the role of medication adherence in poor glycemic control among a genera adult population with diabetes. PLoS One 2014;9:e108145.

65. Rabba AK, Aljiris WS, Ahmed NJ, et al. Medication adherence' in type 2 diabetic patients: a study in Saudi Arabia. 2017.

66. Polonsky WH, Henry RR. Poor medication adherence in type 2 diabetes: recognizing the scope of the problem and its key contributors. Patient Prefer Adherence 2016;10:1299-307.

67. Fukuda $\mathrm{H}$, Mizobe M. Impact of nonadherence on complication risks and healthcare costs in patients newly-diagnosed with diabetes. Diabetes Res Clin Pract 2017;123:55-62.

68. Gatwood JD, Chisholm-Burns M, Davis R, et al. Differences in health outcomes associated with initial adherence to oral antidiabetes medications among veterans with uncomplicated Type 2 diabetes: a 5-year survival analysis. Diabet Med 2018;35:1571-9.

69. IMS Institute for Healthcare Informatics. Improving Type 2 Diabetes therapy compliance and persistence in the Kingdom of Saudi Arabia. 2016.

70. Roebuck MC, Kaestner RJ, Dougherty JS. Impact of medication adherence on health services utilization in medicaid. Med Care 2018;56:1-73.

71. Simard P, Presse N, Roy L, et al. Association between metformin adherence and all-cause mortality among new users of metformin: a nested case-control study. Ann Pharmacother 2018;52:305-13.

72. Schectman JM, Nadkarni MM, Voss JD. The association between diabetes metabolic control and drug adherence in an indigent population. Diabetes Care 2002;25:1015-21.

73. Kini V, Ho PM. Interventions to improve medication adherence: a review. JAMA 2018;320:2461-73. 